\title{
A “querela dos métodos” de alfabetização no Brasil: contribuições para metodizar o debate
}

\section{The "methods querela" on literacy in Brazil: contribuitions to methodize the debate}

\author{
Maria do Rosário Longo MORTATTI
}

\section{RESUMO}

Com o objetivo de contribuir para o debate em torno dos métodos de alfabetização no Brasil e como resultado de pesquisa documental sobre o tema, é apresentada e problematizada uma das mais recentes propostas para alfabetização de crianças, a centrada no método fônico. São apresentadas as principais características dessa proposta recente assim como os principais equívocos nela contidos, inter-relacionando-a com as demais propostas e métodos de alfabetização apresentadas ao longo da história do ensino inicial de leitura e escrita no Brasil, desde o final do século XIX.

Palavras-chave: história da alfabetização, métodos de alfabetização, método fônico.

\section{ABSTRACT}

In order to contribute for the debate concerning literacy methods, in Brazil, as a result of documental research it is presented and discussed one of the most recent proposals for children literacy, that is based upon phonic method. They are presented the main characteristics of this recent proposal as so as its main mistakes in connection with others literacy methods proposed in the history of literacy in Brazil, since the end of $19^{\text {th }}$ century.

Index Terms: history of literacy, literacy methods, phonic method.

\section{RÈSUMÈ}

Afin de contribuer pour le débat sur les méthodes d'alphabétisation au Brésil et comme résultat du recherche documental, c'est presentée et discutée une proposition actuelle pour l'alphabétisation de l'enfants, cette fondée sur la méthode phonique. Ce sont presentés les caractéristiques principales de cette proposition et ses principaux défauts ainsi que ses relations avec autres propositions dans l'histoire de l'alphabétisation au Bresil, à partir du XIXe siècle.

Mots clés: histoire de l'alphabétisation, méthode d'alphabétisation, méthode phonique. 
A oposição antigo/moderno, que é um dos conflitos através dos quais as sociedades vivem suas relações contraditórias com o passado, agudiza-se sempre que se trata de lutar contra um passado recente, um presente sentido como passado, ou quando a querela dos antigos e modernos assume as proporções de um ajuste de contas entre pais e filhos.

(Jacques Le Goff)

O passado é lição para se meditar, não para reproduzir.

(Mário de Andrade)

\section{Introdução}

Como alfabetizar? Por onde começar? Pelos nomes das letras, pelos sons das letras, pelas sílabas, por palavras-chaves, por sentenças ou por histórias? Essas são as primeiras e mais urgentes perguntas feitas por aqueles cuja tarefa é o ensino inicial da leitura e escrita a crianças.

No caso brasileiro, porém, essas são uma espécie de eco de outra e "matricial" pergunta: "Como enfrentar as dificuldades tanto de nossas crianças em aprender a ler e escrever quanto de nossos professores em lhos ensinar?" ou, em termos mais recentes e abrangentes: "Como enfrentar o grave problema do fracasso da escola e da educação em nosso país?”. Essa pergunta matricial se refere a um aparentemente mesmo e persistente problema político e social, cuja busca de respostas vem movendo a história da escola e do ensino inicial da leitura e escrita no mundo ocidental e, em particular, no Brasil, desde pelo menos o final do século XIX.

Apresentar e problematizar os principais aspectos de uma das respostas mais recentes a essa pergunta - a proposta centrada no método fônico — inter-relacionando-a com as demais apresentadas ao longo da história da alfabetização no Brasil, a fim de contribuir para metodizar o atual debate em torno dos métodos de alfabetização no Brasil gerado por essa proposta, esses são os procedimentos e os objetivos deste artigo. 


\section{A histórica "querela dos métodos"}

A partir especialmente das duas últimas décadas do século XIX, os esforços de instauração de uma nova ordem política e social no Brasil, que culminaram na instalação do regime republicano, foram acompanhados de esforços de organização de um sistema de instrução pública de acordo com os ideais do novo regime político. A escola se consolidou, então, como lugar institucionalizado para o preparo das novas gerações, prometendo acesso de todos à cultura letrada, por meio do aprendizado da leitura e escrita. A alfabetização se tornou fundamento da escola obrigatória, laica e gratuita; e a leitura e a escrita se tornaram, "definitivamente", objeto de ensino e aprendizagem escolarizados, ou seja, submetidos à organização sistemática, tecnicamente ensináveis e demandando preparação de profissionais especializados. Desse ponto de vista, a alfabetização se apresenta como o signo mais evidente e complexo da relação problemática entre educação e modernidade, tornando-se o principal índice de medida e testagem da eficiência da educação escolar.

Decorridos mais de cem anos de implantação do modelo republicano de escola e de significativas mudanças de ordem política, social e cultural ocorridas ao longo do século XX, tem-se hoje no Brasil (embora não somente aqui), como ponto consensual de debates e denúncias relativas à educação, o fracasso da escola pública brasileira em dar conta de sua tarefa histórica fundamental e, portanto, de responder às urgências sociais e políticas que lhe dão sustentação. A recorrência desse fracasso vem sendo apresentada como problema estratégico a demandar soluções urgentes, mobilizando administradores públicos, legisladores do ensino, intelectuais de diferentes áreas de conhecimento, educadores, professores e gerando acirradas discussões em torno do ensino inicial da leitura e escrita. 
A face mais visível dessas discussões se foi configurando na questão dos métodos de alfabetização ${ }^{1}$ ou "querela dos métodos", como passou a ser denominada. Em diferentes momentos históricos, diferentes sujeitos movidos por diferentes urgências sociais e políticas, sempre alegando se basear nas mais "modernas verdades científicas", passaram a apresentar versões de seu presente e de seu passado (recente), acusando de "antigos" e "tradicionais" os métodos então utilizados e propondo em sua substituição "novos" e "revolucionários" métodos (de alfabetização).

Em cada momento histórico, a mudança exigiu (e continua exigindo), dos sujeitos promotores dessa querela, operações de diferenciação qualitativa, mediante reconstituição sintética do passado (e, em particular, do passado recente, sentido como presente, porque operante no nível das concretizações), a fim de homogeneizá-lo e esvaziá-lo de qualidades e diferenças, identificando-o como portador do antigo - indesejável, decadente e obstáculo ao progresso _, buscando definir o novo - melhor e mais desejável - ora contra, ora independente em relação ao antigo, mas sempre e inevitavelmente a partir dele.

Para viabilizar a mudança, torna-se, assim, necessário produzir uma versão do passado e desqualificá-lo, como se se tratasse de uma herança incômoda, que impõe resistências à fundação do novo, especialmente quando a filiação decorrente (embora, muitas vezes, não assumida) da tradição atuante no presente ameaça fazer voltarem à cena os mesmos personagens do passado, que seus herdeiros desejam esquecer, rever ou aprimorar.

Como decorrência dessas disputas, em cada momento histórico, considero que se funda uma "nova tradição", centrada em um sentido que se tornou hegemônico, porque oficial, mas não único, nem homogêneo, nem

\footnotetext{
${ }^{1}$ Os métodos de alfabetização, como se sabe, podem ser classificados em dois tipos básicos: sintético (da "parte" para o "todo") e analítico (do "todo" para a "parte"). Dependendo do que foi considerada a unidade lingüística a partir da qual se devia iniciar o ensino da leitura e escrita e do que se considerou "todo" ou "parte", ao longo da história da alfabetização no Brasil, foi-se sedimentando a seguinte subdivisão classificatória desses métodos: métodos sintéticos (de marcha sintética): alfabético, fônico, silábico; e métodos analíticos (de marcha analítica): palavração, sentenciação, historieta, conto.
} 
tampouco isento de resistências, mediadas em especial pela velada utilização de antigos métodos e práticas alfabetizadoras, por meio da utilização de cartilhas, esse privilegiado e perene instrumento de concretização dos métodos de alfabetização ${ }^{2}$.

A história da alfabetização no Brasil se caracteriza, portanto, como um movimento complexo, marcado pela recorrência discursiva da mudança, indicativa da tensão constante entre permanências e rupturas, no âmbito de disputas pela hegemonia de projetos políticos e educacionais e de um sentido moderno para a alfabetização.

Essas são as principais conclusões da inédita pesquisa documental e bibliográfica cujos resultados apresento no livro Os sentidos da alfabetização: São Paulo - 1876/1994 (MORTATTI, 2000a). Com o objetivo de contribuir para a produção de uma história da alfabetização no Brasil que auxilie na compreensão dos problemas do presente, nesse livro apresento uma história do ensino inicial da leitura e escrita na fase inicial de escolarização de crianças, no Brasil, com ênfase na situação paulista, desde o final do século XIX até os dias atuais. Com base em procedimentos de localização, recuperação, reunião, seleção e análise de extenso conjunto de fontes documentais primárias, produzidas por brasileiros, proponho a divisão desse complexo movimento histórico em quatro momentos que considero cruciais, cada um deles marcando um "novo" sentido atribuído à alfabetização, como resultado da "querela dos métodos".

Esses momentos e suas principais características são, muito resumidamente: $1^{o}$. momento (1876 a 1890) — disputa entre defensores do então “novo" método da palavração e os dos "antigos" métodos sintéticos (alfabético, fônico, silábico); $2^{\circ}$. momento (1890 a meados da década de 1920) disputa entre defensores do então "novo" método analítico e os dos "antigos" métodos sintéticos; $3^{o}$. momento (meados dos anos de 1920 a final da

\footnotetext{
${ }^{2}$ A respeito dessa função da cartilha de alfabetização, ver, especialmente, Mortatti (2000b).
} 
década de 1970) — disputas entre defensores dos "antigos" métodos de alfabetização (sintéticos e analíticos) e os dos então "novos" testes ABC para verificação da maturidade necessária ao aprendizado da leitura e escrita, de que decorre a introdução dos "novos" métodos mistos; $4^{o}$. momento (meados da década de 1980 a 1994) - disputas entre os defensores da então "nova" perspectiva construtivista e os dos "antigos" testes de maturidade e dos "antigos" métodos de alfabetização.

Como o ano de 1994 indica apenas o encerramento daquela etapa da pesquisa, uma vez que considero que este quarto momento da história da alfabetização no Brasil se encontra ainda em curso, em livro e artigo posteriores (MORTATTI, 2004; 2007) apresento algumas características mais recentes deste momento. E, como já anunciei, em continuidade aos anteriores, neste artigo me detenho em apresentar e problematizar os principais aspectos da resposta centrada no método fônico, mediante análise dos principais aspectos da configuração textual ${ }^{3}$ do livro em que é apresentada essa proposta.

\section{A atual proposta do método fônico}

Nos primeiros anos deste século, apoiados tanto nos resultados de avaliações de instituições e organismos nacionais e internacionais, realizadas com o objetivo de verificar o desempenho escolar de nossos alunos do ensino fundamental e médio, quanto nos exemplos de países desenvolvidos, pesquisadores brasileiros passaram a buscar novas explicações e propostas de solução para a "crise da alfabetização" no Brasil.

Dentre essas propostas, vem ganhando destaque a apresentada por Alessandra e Fernando Capovilla, especialmente no livro Alfabetização: método fônico.

\footnotetext{
${ }^{3}$ Essa expressão designa um conceito que cunhei com a finalidade de contribuir para a abordagem do conjunto de aspectos que devem ser considerados quando se busca compreender o sentido de um texto. A esse respeito, ver, especialmente: Mortatti (2000a).
} 
Os autores são psicólogos, professores universitários e pesquisadores com formação e atuação na área de psicologia experimental. A primeira tem pós-doutorado em Psicologia Experimental, pela Universidade de São Paulo (USP) - Brasil, e o segundo é Ph.D. pela Temple University - EUA e livredocente em neuropsicologia pela USP; e ambos atuam no Laboratório de Neuropsicolingüística Cognitiva Experimental dessa universidade brasileira, respectivamente, como pesquisadora associada e como chefe. Além de outras atividades que desenvolvem e de outras publicações, são autores ou coautores de livros e artigos, em que apresentam resultados de suas pesquisas, relativas ao método fônico e a vários outros temas das áreas de "Fundamentos e Medidas da Psicologia" e de "Avaliação de Desenvolvimento e Distúrbios de Cognição e Linguagem com Intervenção Preventiva e Remediativa".

O livro em questão teve, até o momento, quatro edições: $1^{\mathrm{a}}$., em 2002; $2^{\mathrm{a}}$., em 2003; $3^{\mathrm{a}}$., em 2004; e $4^{\mathrm{a}}$. (revisada e ampliada), em 2007. Desde sua $1^{\mathrm{a}}$. edição, é publicado por Memnon Edições Científicas Ltda., com sede na cidade de São Paulo e fundada há poucos anos, pelo que se pode presumir das informações localizadas. Esse livro figura em primeiro lugar na relação dos "mais vendidos" pela editora, que publicou, até o momento de redação deste artigo, 39 livros na área de fonoaudiologia, psicologia, psicopedagogia e educação, "focados no tema desenvolvimento infantil" e dentre os quais se encontram vários publicados ou organizados pelos autores do livro em questão.

$\mathrm{Na} 3^{\mathrm{a}}$. edição, de 2004, o livro Alfabetização: método fônico tem formato grande $(21 \times 28 \mathrm{~cm})$ e duas orelhas com fotos e dados sobre os autores. No centro da capa, com fundo amarelado, constam nomes dos autores, nomes de quatro colaboradores, título do livro e nome da editora. No cabeçalho e no rodapé, tem-se uma seqüência de reproduções, provavelmente de

\footnotetext{
${ }^{4}$ Informações disponíveis na Plataforma Lattes - CNPq e nas duas orelhas da $3^{\text {a }}$. edição do livro em questão.
} 
ilustrações de livros antigos, dispostas em duas tiras horizontais e sugerindo a seqüência evolutiva do aprendizado da leitura e escrita. Essa seqüência e disposição de imagens se repetem na quarta-capa, em cujo centro se encontram um texto com chamada sobre o conteúdo do livro e os logotipos das agências e instituições financiadoras da pesquisa e/ou da publicação - Coordenação de Aperfeiçoamento de Pessoal de Nível Superior (Capes), Fundação de Apoio à USP (FUSP), Fundação de Amparo à Pesquisa do Estado de São Paulo (Fapesp), Conselho Nacional de Desenvolvimento Científico e Tecnológico (CNPq) - e da editora Memnon.

Na capa da $4^{\text {a }}$. edição, de 2007, que conta, ainda, com apoio do Instituto Nacional de Estudos e Pesquisas Educacionais Anísio Teixeira (Inep), foram efetuadas radicais mudanças. Além do título do livro, têm-se apenas os nomes dos dois autores e o logotipo da editora. Essas informações estão compostas sobre a ilustração, com cores fortes e traços mais atuais, que representa uma sala de aula, pintada com diferentes tons de verde, na qual se encontram uma professora e vários alunos-crianças de diferentes etnias, sentados em carteiras escolares, com lápis e cadernos a sua frente; todos trajam blusas amarelas e calças azuis, com expressão alegre e sorridente, e olhares voltados para uma das alunas, que ostenta, com os braços erguidos, uma placa com a informação: " 4 a . edição revisada ampliada". 5

Os autores apresentam, como epígrafe, um trecho de carta do apóstolo São Paulo, e, em seguida, agradecimentos a: agências de fomento à pesquisa, direção de instituições universitárias, secretarias de educação, um dos prefeitos e um dos vereadores da cidade de Marília-SP, colegas e equipe de trabalho, escolas, professores e alunos de ensino fundamental.

$\mathrm{Na} 2^{\mathrm{a}}$. edição, de 2003, foi acrescentada uma apresentação ( 2 p.), na qual os autores destacam a "clara superioridade" do método fônico, demonstrada pela "revisão de toda a bibliografia publicada sobre alfabetização nos

\footnotetext{
${ }^{5}$ Devido ao limite de páginas deste artigo, não será possível abordar em detalhes todas as características das quatro edições do livro.
} 
últimos 80 anos", de que resulta sua recomendação oficial por renomados “organismos internacionais" e sua exitosa adoção oficial em países “[...] que se destacam mundialmente pela qualidade de sua alfabetização e ensino fundamental, como França, Estados Unidos, Canadá, Inglaterra, Itália, Austrália, Escócia, Irlanda, Suécia, Noruega, Bélgica, Finlândia, Chile, Cuba, Israel e Portugal”. (CAPOVILLA; CAPOVILLA, 2003). ${ }^{6} \mathrm{E}$ informam que o livro se destina à utilização como “[...] Livro do Professor e explica todos os fundamentos científicos do método fônico, bem como os modelos teóricoconceituais e as mais recentes descobertas científicas nacionais e internacionais em que se baseia." Contém, ainda, instruções e explicações para implementação, pelo professor, em sala de aula, de atividades fônicas — "introdução sistemática de correspondências grafofonêmicas", descritas nos dois volumes do "Livro do Aluno" - e metafonológicas - "exercícios para o desenvolvimento da consciência fonológica". (CAPOVILLA; CAPOVILLA, 2003)

$\mathrm{Na} 3^{\mathrm{a}}$. edição, de 2004, os autores acrescentam uma outra e mais longa apresentação intitulada "Por que o Brasil precisa, mais que nunca, do Método Fônico" (26 p.), em que destacam o sucesso editorial do livro e reafirmam tanto o pioneirismo e ousadia de sua proposta quanto a defesa do método fônico. Para isso, atualizam e problematizam dados sobre o fracasso escolar em alfabetização na década 1995-2004, no Brasil, reiteram críticas tanto aos Parâmetros curriculares nacionais (PCN) (1997) quanto ao construtivismo, e reapresentam resultados de experiências internacionais e pesquisas nacionais e internacionais sobre alfabetização.

Explicam, ainda, que o capítulo "Por que a educação brasileira precisa do Método fônico", apresentado na $1^{\text {a }}$. edição do livro, continua "válido", por ser "pioneiro, ousado e de grande importância histórica" e por abordar

\footnotetext{
${ }^{6}$ Nesta e nas demais citações extraídas dessa apresentação, deixo de apresentar essa informação, porque as páginas não são numeradas, no original; procedo da mesma forma nos demais casos em que não houver numeração das páginas no livro em questão.
} 
"a omissão em se corrigirem e se atualizarem os PCN na área de alfabetização", "os quais continuam escandalosamente errôneos e na contramão da História, bem como as terríveis conseqüências desses erros e anacronismos para a população escolar brasileira", sempre reiterando exemplos bem sucedidos de países desenvolvidos (CAPOVILLA; CAPOVILLA, 2004).

Os autores enfatizam que essa apresentação à $3^{\mathrm{a}}$. edição termina com uma "nota de esperança, ancorada no crescente reconhecimento de nossas posições teóricas e de sua efetiva e crescente implementação", criticando duramente o construtivismo, denunciando "o claríssimo racha do establishment construtivista" e elogiando o que consideram "mea culpa" dos "expoentes do construtivismo dominante", frente à constatação da "crise de alfabetização" por ele gerada (CAPOVILLA; CAPOVILLA, 2004).

No desenvolvimento de sua argumentação, os autores apresentam "as linhas mestras" do que consideram ser uma "perspectiva histórica", que "lança luz sobre o fenômeno e permite vislumbrar a saída para o fosso em que o Brasil se meteu nos últimos tempos." (CAPOVILLA; CAPOVILLA, 2004).

E, a fim de justificar sua proposta, os autores reiteram duras críticas ao construtivismo, por considerá-lo o modelo adotado para a alfabetização no Brasil, nos PCN e, portanto, o responsável pelo fracasso em alfabetização nas últimas décadas. Essas críticas são dirigidas, enfaticamente, ao que denominam de "método global ou ideovisual patrocinado pelos PCNs construtivistas em alfabetização", que consideram ser um documento "incorreto, anacrônico e contraproducente", responsável pelo "analfabetismo funcional de nossas crianças" e não apenas das escolas públicas. Segundo os pesquisadores, com a adoção desse "método global ou ideovisual" (whole language), nossas crianças "foram privadas de instruções metafonológicas e fônicas explícitas e sistemáticas" e "não têm consciência fonêmica e conhecimento das relações grafema-fonema suficientes para mapear a fala por meio 
da escrita e para recuperar a fala interna [...] a partir dessa escrita." (CAPOVILLA; CAPOVILLA, 2004).

Após repetidas e detalhadas explicações sobre sua posição teórica e sobre exemplos de "ministérios da educação de países civilizados", em forma de desafio e em tom de sermão religioso, os autores concluem a apresentação da $3^{\mathrm{a}}$. edição do livro com uma exortação ao Ministério da Educação de nosso país e com um pedido de bênção a Deus.

Dentre as 95 referências bibliográficas que seguem a "Apresentação à terceira edição": $42 \%$ são de artigos, capítulos de livros e livros que têm A. Capovilla e F. Capovilla como autores, ou co-autores, ou organizadores/editores; 25\% são de documentos oficiais brasileiros e estrangeiros; $23 \%$ são de publicações de autores estrangeiros; e $8 \%$ de publicações de outros autores brasileiros.

$\mathrm{Na} 4^{\text {a }}$. edição, de 2007, é acrescentada mais uma apresentação (40 p.), em que os autores reiteram suas críticas e enfatizam o tom provocativo das apresentações anteriores.

O conteúdo que se segue a essas apresentações tem características oscilantes entre relatório de pesquisa e manual do professor/livro do aluno e está organizado em duas partes, intituladas, respectivamente: "Por que a educação brasileira precisa do Método Fônico" (98 p.) e "Implementando o método fônico" (295p.).

$\mathrm{Na}$ primeira parte, os autores informam que o livro resulta da "colaboração entre pesquisadores da Universidade de São Paulo e professores da primeira série do ensino fundamental de escolas públicas" e "torna disponíveis, para a Educação Brasileira, procedimentos avançados e eficazes para promover a alfabetização que resultam dos mais recentes desenvolvimentos da pesquisa internacional na área de aquisição de leitura e escrita" (CAPOVILLA; CAPOVILLA, 2004, p. 9).

Expõem, ainda, as justificativas de sua proposta, com repetida ênfase em "Exemplos de parâmetros curriculares de países desenvolvidos e com 
alto desempenho em leitura", e os fundamentos científicos do método fônico, com repetida ênfase na crítica ao construtivismo, seguindo-se as referências bibliográficas.

Na segunda parte, tem-se o detalhamento, para o professor, da proposta de implementação do método fônico, com 130 "atividades diárias de alfabetização". Nessa parte, as letras têm seu tamanho aumentado ainda mais em relação às da primeira parte, que, por sua vez, são maiores do que as das apresentações, que antecedem o sumário.

Deve-se ressaltar, ainda, que, ao longo das edições do livro, vão-se tornando mais evidentes tanto os destinatários privilegiados pelos autores as autoridades educacionais brasileiras, que, no plano político, devem adotar oficialmente a proposta a ser aplicada pelos alfabetizadores, como executores no plano didático-pedagógico - quanto o objetivo de, pela insistente repetição e pelo tom cada vez mais incisivo, persuadir esses destinatários de que a proposta contida no livro deve substituir o que consideram a atual "política de alfabetização" em nosso país, baseada em "crenças pedagógicas terceiromundistas".

\section{Novos velhos equívocos}

De um ponto de vista histórico, inter-relacionando o que expus sinteticamente nos dois tópicos anteriores, é possível concluir que, apesar das boas intenções anunciadas pelos autores de Alfabetização: método fônico, muitas das afirmações em que buscam sustentar essa proposta carecem de rigor teórico e de legitimidade científica; e os principais argumentos que utilizam para defender sua proposta podem ser também utilizados para questioná-la.

Embora os autores a anunciem como uma "boa-nova", não se trata de uma proposta nem "nova", nem "pioneira", nem "solução científica efetiva", com "demonstrada eficácia, cientificidade e atualidade". 
Como já informei, o método fônico é um método de alfabetização caracterizado por marcha sintética conhecido no Brasil desde pelo menos o século XIX. A partir do que considerei o $2^{\circ}$. momento crucial na história da alfabetização no Brasil, os métodos sintéticos foram veementemente criticados e combatidos por aqueles que propuseram e defenderam os métodos de marcha analítica. A principal crítica que, desde então, se passou a fazer aos métodos sintéticos é a de que eles impedem que a criança apreenda o sentido do que se lhe oferece no momento inicial da aprendizagem da leitura; por isso "[...] infernaram a aprendizagem de nossos antepassados e levaram à afirmação brutal do "la letra con sangre entra'." (KÖPKE, 1896, p. 30). Deve-se lembrar, ainda, que, durante o século XX, já não se tratou mais de tendência predominante a proposição e a aplicação de métodos sintéticos ou analíticos puros, mas de métodos mistos (analítico-sintéticos ou sintéticosanalíticos).

Essas informações permitem considerar não-verdadeiras muitas das afirmações dos autores, em especial: "método alfabético-silábico [é] (o avô do método fônico)"; e "A revisão de toda a bibliografia publicada sobre alfabetização nos últimos 80 anos demonstrou a clara superioridade do método fônico". Permitem, ainda, apontar o desconhecimento e os equívocos contidos nos pressupostos dos autores relativos ao que denominam "levantamento da História da Alfabetização internacional recente", que afirmam, repetidas vezes, ser comprobatória da cientificidade de sua proposta.

Por essas razões, também não se sustenta a afirmação dos autores de que uma "crise nacional do analfabetismo funcional [...] se abateu sobre o Brasil no último quarto de século." Como já destaquei, essa crise não é característica apenas do "último quarto de século", embora tenha assumido feições específicas neste momento histórico. Contrariamente ao que os autores afirmam, sua crítica ao construtivismo considera somente parte do "conhecimento científico da última década", justamente a que serve para demonstrar e confirmar os pressupostos que os autores consideram auto- 
explicativos e que repetem insistentemente, a fim de persuadir seus destinatários privilegiados, omitindo - talvez por ignorá-los — outros tantos e importantes resultados de pesquisas científicas de reconhecimento internacional e financiadas por igualmente reconhecidas agências brasileiras de fomento à pesquisa.

E, embora os autores venham-se esforçando por "demonstrar com clareza e solidez a inteira responsabilidade histórica do construtivismo na desorganização do ensino da leitura e escrita no último quarto de século", esse esforço discursivo resulta em frases de efeito com argumentos pouco claros e pouco sólidos, tais como: essa situação se deveu a um "tempo de obscuridade pré-científica", resultante do "abandono da pedagogia tupiniquim ao construtivismo massificante", de "25 anos da unanimidade tupiniquim em torno do construtivismo" e "sua obtusa incompreensão da importância dos métodos de alfabetização".

Também não se sustenta a afirmação de que a responsabilidade pelo "analfabetismo funcional de nossas crianças" é do "método global ou ideovisual patrocinado pelos PCNs construtivistas em alfabetização". Como se sabe, embora o construtivismo seja base teórica predominante nos PCN, sua oficialização não o tornou "unanimidade na prática alfabetizadora", seja porque não há, de um ponto de vista teórico rigoroso, uma didática construtivista, nem um método construtivista de alfabetização, seja porque, mesmo com a hegemonia do pensamento construtivista no Brasil, continuaram a ser utilizadas cartilhas, que, novas ou antigas, sempre contêm concretização de métodos (sintéticos, ou analíticos, ou mistos) de alfabetização, os quais, portanto, nunca deixaram de ser utilizados por alfabetizadores, nem mesmo no "último quarto de século". Além disso, nem os PCN, nem a teoria construtivista propõem ou patrocinam o "método global ou ideovisual".

Por fim, um dos menos sólidos dos argumentos apresentados pelos autores é o contido na seguinte afirmação: "a solução encontrada pelos países que amargaram crise semelhante à brasileira é perfeitamente válida, 
também, para o Brasil”. Essa afirmação se baseia em raciocínio sofismático, segundo o qual o que serve para alguns países desenvolvidos em determinado momento histórico e como resposta a suas necessidades específicas, serve para todos os outros subdesenvolvidos ou em desenvolvimento, independentemente das diferenças históricas, políticas, sociais, culturais e lingüísticas entre esses países e de suas necessidades específicas. Trata-se apenas de imitar modelos resultantes de pesquisas e necessidades de outros, como se se tratasse de problemas universais idênticos, com soluções igualmente universais e idênticas.

Especificamente desses argumentos, decorrem, por sua vez, as seguintes afirmações: "os devaneios construtivistas se revelaram, de fato, pesadelo sofrido para gerações e gerações de brasileiros incompetentes a engrossar as filas de desempregados" e, com a adoção oficial do método fônico, "a educação brasileira pode dar a volta por cima sem ter de esperar décadas até a melhoria de fatores macroeconômicos e socioculturais". De acordo com essas afirmações, também baseadas em raciocínio sofismático e que sintetizam o objetivo político dos autores, a alfabetização se restringe a uma questão de métodos (sintéticos ou analíticos) e as possibilidades de os brasileiros conseguirem emprego dependem unicamente da opção por um ou outro desses métodos, embora, contraditoriamente, também afirmem que a educação não depende dos "fatores macroeconômicos e socioculturais".

Em síntese, do ponto de vista histórico que aqui proponho, os principais equívocos dos autores de Alfabetização: método fônico podem ser assim resumidos:

- o método fônico não é "neto" do método alfabético-silábico, mas seu irmão caçula, para permanecermos na metáfora parental; o método fônico, portanto, não é um novo método de alfabetização, não "está anos luz à frente do método alfabético-silábico do passado" e as semelhanças entre eles são muito maiores do que a mera "ênfase no som da fala"; 
- as 130 "atividades diárias" apresentadas pelos autores para implementação do método fônico não apresentam diferenças significativas em relação ao padrão histórico das tradicionais cartilhas de alfabetização que se baseiam em métodos sintéticos;

- a (re-)apresentação desse método e de atividades para sua implementação como algo "novo" representa, de um ponto de vista histórico, um anacronismo;

- a proposta centrada no método fônico não é a única atualmente apresentada para alfabetização, e seus propositores não são os únicos a afirmarem, no presente, ou a terem afirmado, no passado, basearem-se em "evidências científicas", especialmente nas fundamentadas na psicologia e suas diferentes vertentes, em particular a psicologia experimental e a piagetiana;

- a revisão de "toda a bibliografia publicada sobre alfabetização nos últimos 80 anos" não "demonstra a clara superioridade do método fônico";

- se há uma "crise brasileira da alfabetização", ela não ocorre somente no último quarto de século, e sua causa não pode ser atribuída, de forma simplista, à "unanimidade tupiniquim em torno do construtivismo", que, por sua vez, não ocorreu;

- assim também não se pode imputar aos "devaneios construtivistas" a responsabilidade por "gerações e gerações de brasileiros incompetentes a engrossar as filas de desempregados", assim como não é o método fônico (nem qualquer outro método de alfabetização) a solução milagrosa para os problemas brasileiros;

- por mais que os autores insistam em tratar a alfabetização como uma questão meramente técnica, não se podem considerar totalmente desvinculados entre si educação, alfabetização e "fatores macroeconômicos e socioculturais". 


\section{Novo velho discurso}

Considerando a busca de autoridade moral, religiosa e política de profeta, que, convencido de estar inspirado pela divindade, em seu nome nos revela a verdade, a boa nova e o advento de um novo tempo, considerando o tom grandiloqüente e messiânico assim como a argumentação tautológica, sofismática e, por vezes, nada elegante - com uma profusão de adjetivos desqualificativos, mas sem críticas substantivas e devidamente fundamentadas ao construtivismo, e outra profusão de adjetivos qualificativos com explícitos auto-elogios - , pode-se concluir que os autores do livro em questão (e seus replicantes e/ou acólitos na academia e na mídia) apresentam sua proposta como se fosse a verdade científica revelada e o fazem por meio de um discurso característico da "retórica de púlpito", como tal, ideológico, autoritário e pseudocientífico.

Trata-se de um tipo de discurso em que não cabe diálogo, porque nele não se pode tolerar a reversibilidade dos papéis de locutores e interlocutores na interação. Por se pretender não-polêmico, é no domínio exclusivo do locutor, pela "ilusão de reversibilidade" e pela tendência à monossemia que se buscam controlar seus sentidos. ${ }^{7}$

Trata-se, assim, de um tipo de discurso que serve a um propósito ideológico, cujo autor, como um deus ou seu representante, define-se a si mesmo como sujeito que nomeia, mas não admite ser nomeado, se não como repetição dos nomes por ele autorizados. Como tal, trata-se de um tipo de discurso autoritário, que tem sua condição de existência identificada com o pressuposto do desnivelamento fundamental na relação locutordestinatário: o locutor está no plano espiritual (ou científico, no caso em questão) e, por isso, apresenta-se como infalível, infinito e todo-poderoso; o destinatário está no plano temporal (ou leigo, no caso em questão), e, por

\footnotetext{
${ }^{7}$ As considerações contidas neste e nos quatro parágrafos seguintes se baseiam em Orlandi (1987) e Althusser (1974).
} 
isso, é falível, finito e dotado de poder dependente das benesses distribuídas pelo locutor.

Essa assimetria fundamentada no princípio da não-reversibilidade é o móvel para a salvação e a fé, respectivamente, pela e na ciência identificada com a religião. Assim como no discurso religioso a voz de um deus é falada na do profeta-pregador, no discurso pseudocientífico, a voz do saber é falada na do pseudocientista-propagandista, que mistifica a verdade como revelada, a serviço de finalidades reais que não podem ser explicitadas, sob pena de inviabilizar esse discurso e os efeitos pretendidos.

Como a linguagem é utilizada para agir sobre os destinatários e neles desencadear determinadas ações práticas, desses destinatários se requer, portanto, apenas disposição para mudar, em direção à salvação, e fé na verdade científica revelada. Deles não se requer que reflitam ou questionem, pois a definição das ações e das formas de sua execução cabem ao deus ou a seu representante, o profeta-pregador/pseudocientista-propagandista, a quem devem obedecer.

Trata-se, portanto, de um discurso mobilizador do silêncio obediente, cuja função mais característica não é impedir as pessoas de falar ou agir, mas é sobretudo obrigá-las a dizer e fazer o que não querem ou não poderiam dizer ou fazer, se não com base na fé.

Assim, é possível compreender o discurso contido em Alfabetização: método fônico, como também vem sendo compreendido por outros pesquisadores brasileiros e estrangeiros, críticos desse método e das afirmações e argumentos que sustentam a proposta dos autores.

Assim é possível, ainda, constatar que a ousadia e o pioneirismo que os autores de Alfabetização: método fônico se auto-atribuem consiste, de fato, em apresentar como "novo" e "solução científica efetiva" o que não o é, em supor que a reposição do discurso sobre a eficiência e cientificidade do método fônico possa confundir e silenciar a todos os que conhecem e produzem pesquisas na área, as quais os autores desconsideram, assim como 
desconsideram a necessidade de diálogo com a comunidade acadêmica brasileira diretamente envolvida nos problemas relativos à alfabetização no Brasil.

Exceção feita, em especial, às marcas religiosas e ao ponto de vista centrado na "neuropsicolingüística cognitiva experimental", relacionados com as condições científicas, sociais e culturais deste momento histórico, trata-se, enfim, de um tipo de discurso já fartamente conhecido e utilizado ao longo da história da alfabetização no Brasil, por aqueles que, em cada um dos quatro momentos que proponho, buscaram convencer seus contemporâneos de que eram portadores de nova, científica e definitiva solução para os problemas da alfabetização no país.

\section{Considerações finais}

Grandes são os riscos de abordar o presente. Maior, porém, é a responsabilidade de fazê-lo, quando se considera que a história não é caracterizada nem por ciclos de apogeu e decadência, nem por "eternos retornos", nem por trajetória lineares de progresso em direção ao fim da evolução, e que a abordagem histórica, no âmbito científico, visa primordialmente a compreender, sem disputar julgamentos de valor apriorísticos. E muito maior, ainda, é a responsabilidade de fazê-lo com o objetivo de oferecer uma parcela de contribuição para um debate que deve ser sobretudo rigoroso e conseqüente. A esses riscos se acrescentam tantos outros, quando o historiador é também ele partícipe do presente que aborda historicamente e não se dispõe a engrossar fileiras de santas cruzadas.

Como já explicitei em outras publicações, em minha atuação como professora e pesquisadora venho apresentando e defendendo propostas para a alfabetização (que considero ser a etapa inicial do ensino da língua portuguesa), centradas no interacionismo lingüístico, não em métodos (sintéticos ou analíticos) de alfabetização, nem na perspectiva construtivista. Por isso, 
contrariamente ao que se possa deduzir com raciocínios simplistas, devo advertir que o foco de meus questionamentos neste artigo incide, não apenas no método fônico em si, como se buscasse alimentar a "querela dos métodos", mas na proposta de adoção oficial desse método defendida pelos autores de Alfabetização: método fônico. Meus questionamentos não podem, ainda, ser revertidos automaticamente em argumentos de defesa, nem do construtivismo, nem desse ou de outro dentre os métodos de alfabetização, como se disputasse um lugar como querelante. Assim também meu objetivo de compreender historicamente essa proposta não significa a ela aplicar, benevolente e tolerantemente, o refrão religioso-popular "tudo compreender é tudo perdoar"; assim como não significa me omitir, ou buscar silenciar o debate, com algum tipo de palavra final, como quem se coloca acima das disputas, fingindo ignorá-las.

Com a explicitação desses riscos e dessas ressalvas, posso reafirmar que o método fônico hoje reapresentado como novo e principalmente os argumentos em sua defesa já mostraram ser ineficazes há mais de um século, no Brasil. Por isso, a atual discussão sobre métodos de alfabetização, provocada pela apresentação da proposta dos autores do livro em questão, vem gerando conclusões e decisões equivocadas, com muitos outros prejuízos para o aprendizado de nossas crianças e para a sociedade brasileira. Principalmente porque não se pode aceitar que, de modo isolado e com objetivos salvacionistas, um método possa resolver os problemas da alfabetização, nem que devamos ressuscitar um ou alguns deles. E porque, do modo como vem sendo apresentada e defendida, não se trata de disputa ou "guerra de alfabetizadores", ${ }^{\prime \prime}$ nem de discussão promovida por esses professores ou da qual participem como interlocutores. Trata-se de disputa pela hegemonia de projetos políticos, promovida pelos autores do livro em questão, patrocinada por agências de fomento à pesquisa, replicada por alguns de seus pares

\footnotetext{
${ }^{8}$ Essa expressão foi utilizada como título de artigo em defesa do método fônico, escrito pelo economista Cláudio Moura Castro, e publicado na revista Veja, de 12 mar. 2008.
} 
e/ou acólitos na academia e por seus divulgadores na mídia, cujos destinatários privilegiados são as autoridades educacionais brasileiras, que, no plano político, devem ser persuadidas, a qualquer custo (incluindo lobbies), a adotar oficialmente a proposta visando à sua aplicação por parte dos alfabetizadores.

Essas estratégias e objetivos também não são novos e caracterizaram disputas ocorridas em cada um dos quatro momentos cruciais na história da alfabetização no Brasil, que sintetizo na introdução deste artigo. E talvez por isso mesmo se tenha sedimentado a expressão "querela dos métodos", em referência a essa discussão.

As conclusões e decisões equivocadas são, portanto, decorrências não apenas da proposta de utilização de método de alfabetização de que eu e outros discordamos, mas, sobretudo, do modo "lobístico" como vem sendo defendida essa proposta, do tipo de discurso que a veicula e do suposto segundo o qual, no âmbito da história (não apenas da alfabetização), se possam "virar páginas" por decreto ministerial ou vontade individual, como se o passado (recente) pudesse ser simplesmente descartado, a partir da versão que dele se quer impor.

Isso não significa, porém, que se deva ensinar a ler e escrever "de qualquer jeito". Por ser um processo escolarizado, sistemático e intencional, esse ensino (como o de todas as matérias escolares) não pode prescindir de método, ou seja, de uma seqüência de passos planejados e organizados para o professor ensinar e as crianças conseguirem aprender a ler e escrever. Se a questão dos métodos é importante, não é, porém, a única, nem a mais importante, e não pode ser tratada com efeitos pirotécnicos, desviando a atenção do que é essencial: o fato de que um método de ensino é apenas um dos aspectos de uma teoria educacional relacionada com uma teoria do conhecimento e com um projeto político e social. Trata-se, assim, de pensar mais seriamente em todos os aspectos envolvidos nesse processo complexo e multifacetado que é a alfabetização e nesse que continua sendo nosso maior 
desafio: a busca de soluções rigorosas, consequientes e relativamente duradouras para se enfrentarem as dificuldades de nossas crianças em aprender a ler e escrever e de nossos professores em ensiná-las.

Por todas essas razões, a proposta dos autores tem prestado um desserviço histórico à alfabetização no Brasil, persuadindo talvez apenas os desavisados, ou os de boa-fé, ou os de má-fé, esses cuja expectativa seja partilhar lucros políticos e financeiros.

E como não se trata de escolher entre agradar a Deus ou aos homens, decisões responsáveis sobre os rumos da alfabetização de nossas crianças precisam, enfim, fundamentar-se, não em revelações, profecias ou interesses pessoais, mas em contribuições científicas pelas quais somos responsáveis todos nós, pesquisadores, que, por dever do ofício, assumimos o compromisso social e o dever ético de justificar, com resultados confiáveis, os investimentos públicos que financiam nossas pesquisas e de contribuir para o diálogo respeitoso e produtivo, por um lado, entre nossos pares, no âmbito da comunidade científica (inclusive por meio de avaliação de solicitações de financiamento de pesquisas), e, por outro lado, com autoridades educacionais e com alfabetizadores, que não podem ser tratados como meros executores de propostas de outrem, sobretudo quando a pesquisa envolve aspectos centrais da vida de seres humanos.

Está aqui registrada minha contribuição para metodizar o debate.

\section{Referências bibliográficas}

ALTHUSSER, Louis (1974). Ideologia e aparelhos ideológicos do estado. Trad. J. J. M. Ramos. Lisboa: Presença; São Paulo: Martins Fontes.

CAPOVILLA, Fernando C.; CAPOVILLA, Alessandra G. S. (2003). Alfabetização: método fônico. Colaboradores: Fernanda Silveira e outros. 2. ed. São Paulo; Memnon. 
(2004). Alfabetização: método fônico. 3. ed. São Paulo; Memnon. (Colaboradores: Fernanda Silveira e outros).

(2007). Alfabetização: método fônico. 4. ed. São Paulo: Memnon; Capes/Inep/Fapesp/CNPq.

KÖPKE, João (1896). A leitura analytica (Conferência feita a 1 de março de 1896, no Instituto Pedagógico de São Paulo). São Paulo: Typ. a vapor de Hennies Irmãos.

MORTATTI, Maria do Rosário Longo (2000a). Os sentidos da alfabetização: São Paulo - 1876/1994. São Paulo: Editora UNESP; Brasília: MEC/Inep/Comped.

(2000b). Cartilha de alfabetização e cultura escolar: um pacto secular. Cadernos CEDES, 52 (Cultura escolar - história, práticas e representações), p.41-54.

(2004). Educação e letramento. São Paulo: Editora UNESP.

(2007). Letrar é preciso, alfabetizar não basta... mais?. In: SHOLZE, Lia; ROSLING, Tânia (Org.). Teorias e práticas de letramento. Brasília: Inep; Passo Fundo: Editora da Universidade de Passo Fundo, p. 155-168.

ORLANDI, Eni Pulccinelli (1987). O discurso religioso. In: A linguagem e seu funcionamento: as formas do discurso. 2. ed. rev. e aum. Campinas: Pontes. p. 239-262.

\section{AUTORA}

\section{Maria do Rosário Longo MORTATTI}

Universidade Estadual Paulista (UNESP) - Campus de Marília - SP - Brasil Professora Livre-docente e coordenadora do Grupo de Pesquisa "História do ensino de língua e literatura no Brasil"

Fone (14) 3402-1327

Av. Hygino Muzzi Filho, 737, Marília - SP - Brasil

e-mail:mrosario@marilia.unesp.br 
Recebido em maio de 2008. Aprovado em maio de 2008.

\section{Como citar este artigo:}

MORTATTI, Maria do Rosário Longo. A "querela dos métodos" de alfabetização no Brasil: contribuições para metodizar o debate. Revista ACOALFAplp: Acolhendo a Alfabetização nos Países de Língua portuguesa, São Paulo, ano 3, n. 5, 2008. Disponível em: <http://www.acoalfaplp.net>. Publicado em: setembro 2008. 